\title{
Food processing as a risk factor for antimicrobial resistance spread along the food chain
}

Elena-Alexandra Oniciuc ${ }^{1 \#}$, Eleni Likotrafiti ${ }^{2 \#}$, Adrián Alvarez-Molina ${ }^{3}$, Miguel Prieto ${ }^{3,4}$, Mercedes López ${ }^{3,4}$, Avelino Alvarez-Ordóñez ${ }^{3,4 *}$

${ }^{1}$ Faculty of Food Science and Engineering, Dunarea de Jos University of Galati, Galati, Romania.

${ }^{2}$ Department of Food Technology, Laboratory of Food Microbiology, Alexander Technological Educational Institute of Thessaloniki, Thessaloniki, Greece.

${ }^{3}$ Department of Food Hygiene and Technology, Universidad de León, León, Spain.

${ }^{4}$ Institute of Food Science and Technology, Universidad de León, León, Spain.

Keywords: Antimicrobial resistance, food safety, food processing, foodborne pathogens

*Author for correspondence: A. Alvarez-Ordóñez. Phone: 0034 987291274; e-mail:

aalvo@unileon.es

"These two authors equally contributed to the work. 


\begin{abstract}
Farms and food industries rely to a large extent on the use of biocides as disinfectants and other antimicrobial agents and preservatives with antimicrobial properties in order to provide food of high microbiological quality and safe for consumers. However, in the last decades it has become apparent that long-term sub-lethal exposure to these antimicrobial agents can exert a selective pressure leading to the emergence and spread of microbial strains with a reduced susceptibility to the used antimicrobials, which can persistently colonize food-processing environments and recurrently contaminate food. In addition, it may induce resistance to unrelated and clinically relevant antibiotics, in a phenomenon known as cross-resistance. This review aims to provide insights on how antimicrobial resistance emergence and spread can be affected by certain food processing activities and to discuss recent research focused on different pathways through which biocides and other antimicrobials could co-select for bacteria resistant to clinically relevant antibiotics.
\end{abstract}




\section{Introduction}

Antimicrobial resistance (AMR) is currently a global threat that affects human and animal health. Considerable importance is being paid to pathogenic bacteria which have become resistant to different classes of antibiotics in clinical [1,2], veterinary and food related settings [3,4]. Infections caused by antibiotic resistant microorganisms have a significant and increasing economic impact $[1,5,6]$. In addition, other antimicrobials, such as disinfectants, used to control or reduce the bacterial burden in hospitals and agro-food industries are becoming less effective due to the decreased susceptibility to them of the targeted microorganisms [7]. Many researchers are trying to understand the mechanisms through which bacteria, under certain conditions prevailing at farm, industrial and household settings, become resistant or tolerant to a range of antimicrobials. Concerning the food sector, keeping food safe for consumers relies to a large extent on the use of biocides as disinfectants and other preservatives with antimicrobial properties [7,8]. However, use of biocides and other antimicrobials can induce resistance through long-term sub-lethal exposure and exert a selective pressure favoring isolates which harbor AMR genes (which may also be acquired or transferred, in some occasions, by horizontal gene transfer) [9]. In addition, the exposure of bacteria to low concentrations of biocides and other antimicrobials may induce resistance to unrelated and clinically relevant antibiotics, in a phenomenon known as cross-resistance $[7,9]$.

Scarce data is available on the contribution of the food chain to the global burden of infections caused by acquired antimicrobial-resistant bacteria. Potential sources of AMR in the food chain (graphically summarized in Figure 1) are the use and/or overuse of antimicrobials administered to food producing animals [4] that could contribute to the global burden of human AMR infections [1,4]. Also the role of some environmental niches within the food chain acting as potential hotspots for AMR development and persistence of resistant microorganisms, which may then reach the human host $[10,11]$. This review aims to provide insights into the spread of AMR through the food chain and how it can be affected by certain food processing activities and discuss recent research focused on different pathways through which biocides and other antimicrobials could co-select for bacteria resistant to clinically relevant antibiotics.

\section{Determinants of resistance to antimicrobials used in food processing}

Bacteria can respond to different types of selective pressures, including antimicrobials, by undergoing various physiological changes resulting in an acquired tolerance towards the inducing agent and/or other antimicrobial agents in an adaptive response mediated through chromosomal mutations, acquisition of new phenotypes via horizontal gene transfer or through co-/cross-resistance or crossprotection processes $[4,7,12]$. In the food chain, AMR can be acquired when bacteria are challenged with antibiotics, preservatives, heavy metals, antiseptics or disinfectants, among others $[4,13]$. These antimicrobials and food processing aids induce complex bacterial stress responses, commonly triggering the overexpression of efflux pumps, responsible for expelling the antimicrobials from the cell. The relevant efflux systems in Gram-negative bacteria are divided into two groups: primary and

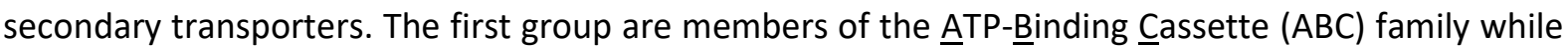

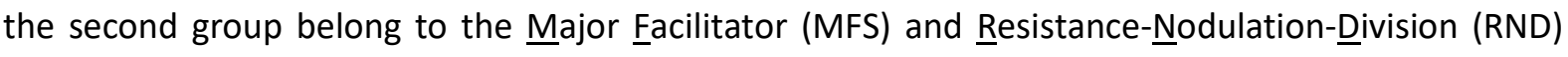
Superfamilies, Small Multidrug Resistance (SMR) and Multidrug and Ioxic compound Extrusion (MATE) families $[14,15]$. Intrinsically, greater tolerance to biocides has been noticed in Gram-negative bacteria due to their inherent outer membrane permeability barrier [13] and to the occurrence of 
certain resistance genes associated with resistance to quaternary ammonium compounds (QAC) such as qacE, qacE $\Delta 1$, qacF, qacG, and qacH [13].

Among different Gram-negative bacterial species, various efflux pumps have been described in Escherichia coli and Salmonella enterica (AcrAB-TolC), Pseudomonas aeruginosa (MexAB-OprM, MexCD-OprJ and MexXY-OprM) and Campylobacter jejuni (CmeABC) [14]. Moreover, a TolC multidrug resistance efflux pump associated with biocide resistance has been also detected in members of the Enterobacteriaceae family $[9,12]$. In Gram-positive bacteria, same family groups predominate as efflux proteins which can transport various biocides and disinfectants as well as unrelated compounds, which may result in a multidrug resistance phenotype of great significance [16]. For example, a norA gene coding for a multidrug efflux pump has been detected in a Lactobacillus pentosus strain [17]. Moreover, Gram-positive bacteria, including Listeria monocytogenes and Staphylococcus aureus, have demonstrated ability to acquire mutations in efflux systems, which are responsible for multidrug resistance phenotypes and reduced susceptibility to biocides $[18,19]$.

\section{Persistence in food processing environments as affected by the usage of antimicrobials}

In the last years, large research efforts have been focused on identifying episodes of microbial persistence (long-term colonization) in food processing environments and equipment and on understanding the mechanisms behind this phenomenon and developing strategies for avoiding it, which would contribute to mitigate the transfer of foodborne pathogens during activities such as slicing, washing, or cleaning. For example, Salmonella spp. strains were shown to persistently contaminate different points across an Irish pork production facility, and changes in their metabolic activity, leading to a phenotypic switch, have been identified allowing their adaptation and survival during food processing [20]. Other observed adaptive responses linked to microbial persistence in food industries include biocide adaption by $C$. jejuni strains embedded within biofilms [21], and effluxmediated cross-resistance to selected antimicrobials, induced in strains of $L$. monocytogenes serotypes $1 / 2 \mathrm{a}$ and $4 \mathrm{~b}$ by exposure to sub-lethal concentrations of benzalkonium chloride compounds (BAC) [22]. Biocide-resistant $L$. monocytogenes strains were also isolated from different processing control points in two tilapia processing factories, and were attributed to incorrect handling of the fillets and to the incorrect application of sanitizing procedures [23]. As to potential control strategies mitigating persistence, researchers have addressed the potential effectiveness of natural antimicrobials, such as oregano essential oil (0.5\%) incorporated in detergent solutions used for hand washing and food contact surface cleaning, as useful antimicrobial alternatives for reducing pathogen survival [24]. Similarly, others have looked on the reduction of E. coli 0157:H7 and Salmonella when washing contaminated gloves (used for harvesting ready-to-eat produce) in levulinic acid and sodium dodecyl sulphate (SDS) solutions [25].

\section{Biocide-induced cross-resistance to antibiotics: implications for food safety}

Biocide-induced cross-resistance to antibiotics has been demonstrated in several occasions (some relevant reports from the last decade are highlighted in Table 1). For example, for $P$. aeruginosa, BACresistant strains obtained after long-term exposure to BAC compounds contained mutations in the $p m r B$ (polymyxin resistance) gene and suffered a series of physiological adaptations contributing to higher tolerance to such antibiotic and others [26]. Other researchers analysed $P$. aeruginosa strains isolated from different industrial surfaces, such as entrance, slaughter-room, cold-room, cuttingroom, freezing tunnel and white-room, of a lamb slaughterhouse or from the lamb products. They 
identified cross-resistance events, specifically detected between triclosan or industrial biocide formulations, such as polyhexamethylene guanidine hydrochloride (PHMG), and different antibiotics [27]. Interestingly, a predictive protocol to measure AMR under biocidal usage has been developed in which cross-resistance occurred in S. aureus and E. coli isolates when exposed to triclosan $(0.0004 \%)$ and to low concentrations of hydrogen peroxide $(0.001 \%)$, while no changes in AMR were observed with exposure to chlorhexidine $(0.00005 \%)$ [28].

The issue of biocides leading to an increase in antibiotic resistance has been investigated in bacteria isolated from organic, dairy and seafood products, or from different manufacturing equipment $[13,29,30]$. Various isolates from Lactococcus spp., Enterobacter spp. and Escherichia spp. have been found to be resistant to both antibiotics and biocides in a survey testing 120 food-related bacterial isolates [30]. Efflux pump genes $a c r B$ and $m d f A$ were found in the majority of Gram-negative isolates while some Escherichia spp. isolates carried also the biocide tolerance gene qacE 1 and the sulphonamide resistance gene sul1 [30].

Exposure to other different physico-chemical stresses at sub-lethal levels (such as salt, ethanol, or UV light) has been also shown to confer AMR onto lactic acid bacteria isolated from naturally-fermented Aloreña table olives $[17,31]$. Resistance was induced in strains of Leuconostoc pseudomesenteroides and Lactobacillus pentosus by different stressors, and different susceptibility patterns induced by such stresses were observed. All physico-chemical stressors applied led to cross-resistance events to antibiotics [31]. In addition, changes in the expression profiles of stress/resistance genes, such as rpsL, recA, srtA, and uvrB were observed, and depended on the type of stressor, targeted gene and lactic acid bacteria used [31]. The same authors analysed the response of th.... pentosus MP-10 strain to various biocides (triclosan and BAC compounds) or antibiotics (amoxicillin, tetracycline and chloramphenicol) to better understand which key factors are involved in antibiotic resistance or biocide tolerance [17]. Significant differences in the expression of three proteins were observed in the proteome of $t$ b.L. pentosus MP-10 strain upon treatment with triclosan: glutamyl-tRNA synthetase was up-regulated, the phosphocarrier protein $\mathrm{HPr}$, which is related to carbohydrate metabolism, was down-regulated, and an oxidoreductase (a member of the aldo/keto reductase family) was not detected [17]. Cross-resistance between biocides and antibiotics led to different stress related

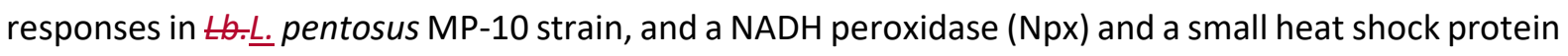
were over-expressed in the amoxicillin and tetracycline-adapted strains, respectively [17].

\section{Minimal processing and AMR}

Fresh-cut fruits, vegetables and different minimally processed ready-to-eat foods have become a growing industry in recent years. However, this sort of products require different mild antimicrobial or preservation treatments to reduce or eliminate bacterial growth without degrading the quality of the end-product [32]. For instance, for fresh-cut fruits and vegetables, the washing of fresh produce is a critical process to remove not only organic load but also to inactivate foodborne pathogens, and many different combinations of treatments have been developed to this end. Some authors have suggested the use of free chlorine solutions for washing cabbage, Romaine or Iceberg lettuces in order to prevent pathogen cross-contamination in produce industries from United States [32]. Although chlorinated washing water samples were microbiologically tested for mesophilic bacterial counts after chlorine neutralization, potential cross-contamination of washed produce could occur due to bacterial survival [32] and little is known on the phenotypic and genotypic backgrounds of these microbial communities under different stress conditions. A water-assisted UV light treatment used in 
combination with chlorine and hydrogen peroxide has been validated for inactivating Salmonella spp. on fresh produce [33]. A similar approach has been applied to reduce $E$. coli $0157: \mathrm{H} 7$ contamination on iceberg lettuce at a commercial processing facility using flume water, peroxyacetic acid and mixed peracid [34]. Results indicated a five-log CFU/mL reduction of E. coli 0157:H7 in wash water with a small organic load when using peroxyacetic acid and mixed peracid treatment [34]. With numerous studies focused on the use of chlorine-based sanitizers, such studies provide valuable information on the use of alternative sanitizers and their increased effectiveness in the presence of various organic loads to be found in the wash water. However, such sanitizers, and other antimicrobial strategies aimed at controlling microbial hazards in ready-to-eat products, should be used under controlled conditions, and in right doses to reduce microbial load but also to avoid foreseen physiological adaptation that could lead to AMR and cross-resistance phenomena between biocides or other antimicrobials/stresses and antibiotics.

\section{Conclusions}

Microbial persistence in food processing environments represents a huge challenge for food safety, as can serve as a source of recurrent contamination of food with resistant microorganisms. Resistance to biocides and other antimicrobials has been considered as one of the main determinants of microbial persistence in food industries. Different pathways have been described in which biocides and other antimicrobials used in low-level concentrations for disinfection or processing purposes could co-select for antibiotic resistant bacteria, with efflux pumps playing a central role in this phenomenon. Nevertheless, the use of antimicrobials remains essential to maintain the hygiene of food processing premises and the microbiological quality and safety of produced foods and, therefore, the cost-benefit of antimicrobial usage in food processing must be considered in any risk assessment exercise. Consequently, cleaning and disinfection protocols and processing regimes should be carefully designed to avoid the exposure of microbes to sub-lethal doses of antimicrobials, which can lead to the emergence and spread of resistant colonizing strains. In addition, there is a need to develop novel and more effective antimicrobial strategies to control the microbial burden in food processing facilities, while preventing the problem of AMR to occur. Some of the new alternatives being proposed by researchers include the use of biocontrol approaches involving phage, competitive exclusion strategies and bacteriocins, among others. These biocontrol agents have demonstrated antimicrobial potential, although there are concerns about their overall efficacy in industrial settings. However, their efficacy is constantly improving with the discovery of novel agents with a broader spectrum of activity or a stronger antibacterial activity, and the likelihood of inducing resistance phenomena is much lower for this type of novel biocontrol strategies.

\section{Acknowledgements}

E.A.O. and E.L. are research fellows funded by the EU-FORA mobility program of the European Food Safety Authority.

Funding by Fundación BBVA and Ministerio de Economía y Competitividad, under grant number AGL2016-78085-P, is acknowledged. 


\section{References and recommended readings}

Papers of particular interest, published within the period of review, have been highlightes as:

*of special interest

** of outstanding interest

1. Allcock S, Young EH, Holmes M, Gurdasani D, Dougan G, Sandhu MS, Solomon L, Török ME: Antimicrobial resistance in human populations: challenges and opportunities. Glob Heal Epidemiol Genomics 2017, 2:1-7.

2. Chong $\mathrm{Y}$, Shimoda S, Shimono N: Current epidemiology, genetic evolution and clinical impact of extended-spectrum $\beta$-lactamase-producing Escherichia coli and Klebsiella pneumoniae. Infect Genet Evol 2018, 61:185-188.

3. Oniciuc E-A, Nicolau Al, Hernández M, Rodríguez-Lázaro D: Presence of methicillin-resistant Staphylococcus aureus in the food chain. Trends Food Sci Technol 2017, 61:49-59.

4. Manyi-Loh C, Mamphweli S, Meyer E, Okoh A: Antibiotic use in agriculture and its consequential resistance in environmental sources: Potential public health implications. Molecules 2018, 23:1-48.

5. Woon S-A, Fisher D: Antimicrobial agents - optimising the ecological balance. BMC Med 2016, 14:114.

6. Tacconelli E, Sifakis F, Harbarth S, Schrijver R, van Mourik M, Voss A, Sharland M, Rajendran $\mathrm{NB}$, Rodri'guez-Baño J: Surveillance for control of antimicrobial resistance. Lancet Infect Dis 2017, 18: e99-106.

* This article highlight the need for coordinated surveillance efforts in the human, veterinary and food sectors, in a "One Health" approach, in order to reduce the burden of Antimicrobial Resistance

7. Buffet-Bataillon S, Tattevin P, Maillard J-Y, Bonnaure-Mallet M, Jolivet-Gougeon A: Efflux pump induction by quaternary ammonium compounds and fluoroquinolone resistance in bacteria. Futur Microbiol 2016, 11:81-92.

* This article discusses the relevence of efflux pumps on cross-resistance responses to antibiotics induced by exposure to biocides. In particular, it is focused on how induction of efflux pumps by quaternary ammonium compounds can be responsible for a decreased susceptibility to fluoroquinolones.

8. Whitehead RN, Overton TW, Kemp CL, Webber MA: Exposure of Salmonella enterica serovar Typhimurium to high level biocide challenge can select multidrug resistant mutants in a single step. PLoS One 2011, 6:1-9.

9. Webber MA, Whitehead RN, Mount M, Loman NJ, Pallen MJ, Piddock LV: Parallel evolutionary pathways to antibiotic resistance selected by biocide exposure. J Antimicrob Chemother 2015, 70:2241-2248.

10. Bengtsson-Palme J: Antibiotic resistance in the food supply chain: where can sequencing and metagenomics aid risk assessment? Curr Opin Food Sci 2017, 14:66-71.

11. Karkman A, Do TT, Walsh F, Virta MPJ: Antibiotic-resistance genes in waste water. Trends Microbiol 2017, 12:1-9. 
12. Slipski CJ, Zhanel GG, Bay DC: Biocide Selective TolC-Independent Efflux Pumps in Enterobacteriaceae. J Membr Biol 2018, 251:15-33.

13. Romero JL, Grande Burgos MJ, Pérez-Pulido R, Gálvez A, Lucas R: Resistance to antibiotics, biocides, preservatives and metals in bacteria isolated from seafoods: co-selection of strains resistant or tolerant to different classes of compounds. Front Microbiol 2017, 8:1-16.

14. Blair JMA, Richmond GE, Piddock $\sqcup$ V: Multidrug efflux pumps in Gram-negative bacteria and their role in antibiotic resistance. Future Microbiol 2014, 9:1165-1177.

15. Soto SM: Role of efflux pumps in the antibiotic resistance of bacteria embedded in a biofilm. Virulence 2013, 4:223-9.

16. Schindler BD, Kaatz GW: Multidrug efflux pumps of Gram-positive bacteria. Drug Resist Updat 2016, 27:1-13.

17. Casado Muñoz M del C, Benomar N, Ennahar S, Horvatovich P, Lavilla Lerma L, Knapp CW, Gálvez A, Abriouel $\mathrm{H}$ : Comparative proteomic analysis of a potentially probiotic Lactobacillus pentosus MP-10 for the identification of key proteins involved in antibiotic resistance and biocide tolerance. Int J Food Microbiol 2016, 222:8-15.

18. Foster TJ: Antibiotic resistance in Staphylococcus aureus. Current status and future prospects. FEMS Microbiol Rev 2017, 41:430-449.

19. Meier AB, Guldimann C, Markkula A, Pöntinen A, Korkeala H, Tasara T: Comparative phenotypic and genotypic analysis of swiss and finnish Listeria monocytogenes isolates with respect to benzalkonium chloride resistance. Front Microbiol 2017, 8:397.

20. Martins M, McCusker MP, McCabe EM, O'Leary D, Duffy G, Fanning S: Evidence of metabolic switching and implications for food safety from the phenome(s) of Salmonella enterica serovar Typhimurium DT104 cultured at selected points across the pork production food chain. Appl Environ Microbiol 2013, 79:5437-5449.

21. Techaruvichit P, Takahashi H, Kuda T, Miya S, Keeratipibul S, Kimura B: Adaptation of Campylobacter jejuni to biocides used in the food industry affects biofilm structure, adhesion strength, and cross-resistance to clinical antimicrobial compounds. Biofouling 2016, 32:827-839.

* In this research article it has been demonstrated that exposure of Campylobacter jejuni to various biocides not only can reduce its susceptibility to some antibiotics, but also can increase biofilm formation (biovolume, surface coverage, roughness and surface adhesion force), which undoubtedly can favor microbial persistence in food processing environments.

22. Kovacevic J, Sagert J, Wozniak A, Gilmour MW, Allen KJ: Antimicrobial resistance and coselection phenomenon in Listeria spp. recovered from food and food production environments. Food Microbiol 2013, 34:319-327.

23. Vázquez-Sánchez D, Galvão JA, Oetterer M: Contamination sources, biofilm-forming ability and biocide resistance of Listeria monocytogenes in tilapia-processing facilities. Food Sci Technol Int 2018, 24:209-222.

24. Rhoades J, Gialagkolidou K, Gogou M, Mavridou O, Blatsiotis N, Ritzoulis C, Likotrafiti E: Oregano essential oil as an antimicrobial additive to detergent for hand washing and food contact surface cleaning. J Appl Microbiol 2013, 115:987-994.

25. Erickson MC, Liao JY, Habteselassie MY, Cannon JL: Inactivation of Escherichia coli O157:H7 and Salmonella during washing of contaminated gloves in levulinic acid and sodium dodecyl 
sulfate solutions. Food Microbiol 2018, 73:275-281.

26. Kim M, Hatt JK, Weigand MR, Krishnan R, Pavlostathis SG, Konstantinidis KT: Widely used benzalkonium chloride disinfectants can promote antibiotic resistance. Appl Environ Microbiol 2018, doi: 10.1128/AEM.01201-18.

** In this research article it is demonstrated that benzalkonium chloride co-selects for antibiotic resistant bacteria. In addition, the genetic determinants and adpative mechanisms leading to the observed phenotype are uncovered.

27. Lavilla Lerma L, Benomar N, Casado Muñoz M del C, Gálvez A, Abriouel H: Correlation between antibiotic and biocide resistance in mesophilic and psychrotrophic Pseudomonas spp. isolated from slaughterhouse surfaces throughout meat chain production. Food Microbiol 2015, 51:33-44.

28. Wesgate R, Grasha P, Maillard JY: Use of a predictive protocol to measure the antimicrobial resistance risks associated with biocidal product usage. Am J Infect Control 2016, 44:458464.

29. Gadea R, Fernández Fuentes MÁ, Pérez Pulido R, Gálvez A, Ortega E: Effects of exposure to quaternary-ammonium-based biocides on antimicrobial susceptibility and tolerance to physical stresses in bacteria from organic foods. Food Microbiol 2017, 63:58-71.

** In this research article it is shown that biocide-sensitive bacteria belonging to different species and genus can acquire increased resistance to a range of biocides and antibiotics upon repeated exposure to increasing concentrations of quaternary ammonium compounds.

30. Fernández Márquez ML, Grande Burgos MJ, López Aguayo MC, Pérez Pulido R, Gálvez A, Lucas R: Characterization of biocide-tolerant bacteria isolated from cheese and dairy smallmedium enterprises. Food Microbiol 2017, 62:77-81.

31. Casado Muñoz M del C, Benomar N, Lavilla Lerma L, Knapp CW, Gálvez A, Abriouel H: Biocide tolerance, phenotypic and molecular response of lactic acid bacteria isolated from naturally-fermented Aloreña table to different physico-chemical stresses. Food Microbiol 2016, 60:1-12.

32. Luo Y, Zhou B, Van Haute S, Nou X, Zhang B, Teng Z, Turner ER, Wang Q, Millner PD: Association between bacterial survival and free chlorine concentration during commercial fresh-cut produce wash operation. Food Microbiol 2018, 70:120-128.

33. Guo S, Huang R, Chen H: Application of water-assisted ultraviolet light in combination of chlorine and hydrogen peroxide to inactivate Salmonella on fresh produce. Int J Food Microbiol 2017, 257:101-109.

34. Davidson GR, Kaminski-Davidson CN, Ryser ET: Persistence of Escherichia coli O157:H7 during pilot-scale processing of iceberg lettuce using flume water containing peroxyacetic acid-based sanitizers and various organic loads. Int J Food Microbiol 2017, 248:22-31.

35. Lu J, Jin M, Nguyen SH, Mao L, Li J, Coin LJM, Yuan Z, Guo J: Non-antibiotic antimicrobial triclosan induces multiple antibiotic resistance through genetic mutation. Environ Int 2018, 118:257-265.

36. Nasr AM, Mostafa MS, Arnaout HH, Elshimy AAA: The effect of exposure to sub-inhibitory concentrations of hypochlorite and quaternary ammonium compounds on antimicrobial susceptibility of Pseudomonas aeruginosa. Am J Infect Control 2018, 46:e57-e63.

37. Gadea R, Glibota N, Pérez Pulido R, Gálvez A, Ortega E: Adaptation to biocides cetrimide and 
chlorhexidine in bacteria from organic foods: association with tolerance to other antimicrobials and physical stresses. J Agric Food Chem 2017, 65:1758-1770.

38. Wand ME, Bock $L$, Bonney LC, Sutton JM: Mechanisms of increased resistance to chlorhexidine and cross-resistance to colistin following exposure of Klebsiella pneumoniae clinical isolates to chlorhexidine. Antimicrob Agents Chemother 2017, 61.

39. Soumet C, Méheust D, Pissavin C, Le Grandois P, Frémaux B, Feurer C, Le Roux A, Denis M, Maris $P$ : Reduced susceptibilities to biocides and resistance to antibiotics in food-associated bacteria following exposure to quaternary ammonium compounds. J Appl Microbiol 2016, 121:1275-1281.

40. Karatzas KAG, Webber MA, Jorgensen F, Woodward MJ, Piddock L V., Humphrey TJ: Prolonged treatment of Salmonella enterica serovar Typhimurium with commercial disinfectants selects for multiple antibiotic resistance, increased efflux and reduced invasiveness. J Antimicrob Chemother 2007, 60:947-955.

41. Randall LP, Cooles SW, Coldham NG, Penuela EG, Mott AC, Woodward MJ, Piddock L V., Webber MA: Commonly used farm disinfectants can select for mutant Salmonella enterica serovar Typhimurium with decreased susceptibility to biocides and antibiotics without compromising virulence. J Antimicrob Chemother 2007, 60:1273-1280. 
Table 1. Summary of relevant research studies in the last decade showing evidence of cross-resistance between biocides and clinically relevant antibiotics.

\begin{tabular}{|c|c|c|c|c|}
\hline Reference & Microbial species & Biocides used & $\begin{array}{l}\text { Antibiotics to which } \\
\text { resistance was developed }\end{array}$ & Methodological approach followed \\
\hline [26] & P. aeruginosa & BAC & $\begin{array}{l}\text { Polymyxin B, tetracycline, } \\
\text { ciprofloxacin }\end{array}$ & $\begin{array}{l}\text { BAC-fed bioreactors inoculated with river sediment } \\
\text { selected for resistant } P \text {. aeruginosa. } \\
\text { Adaptive selective experiments were carried out for } P \text {. } \\
\text { aeruginosa strains in the presence of BAC for more } \\
\text { than } 300 \text { generations. }\end{array}$ \\
\hline [35] & E. coli & Triclosan & $\begin{array}{l}\text { Levofloxacin, amoxicillin, } \\
\text { tetracycline and } \\
\text { chloramphenicol }\end{array}$ & $\begin{array}{l}\text { Cells were exposed for } 30 \text { days to triclosan at a } \\
\text { concentration of } 0.2 \mathrm{mg} / \mathrm{L} \text {. }\end{array}$ \\
\hline [36] & Pseudomonas spp. & $\begin{array}{l}\text { Didecyldimonium chloride and } \\
\text { sodium hypochlorite }\end{array}$ & $\begin{array}{l}\text { Colistin, ceftazidime, } \\
\text { amikacin, meropenem, } \\
\text { gentamicin, piperacillin- } \\
\text { tazobactam, ciprofloxacin }\end{array}$ & $\begin{array}{l}\text { The minimal inhibitory concentrations (MICs) of each } \\
\text { antibiotic were compared before and after exposure } \\
\text { to sub-inhibitory concentrations of didecyldimonium } \\
\text { chloride and sodium hypochlorite. }\end{array}$ \\
\hline [37] & $\begin{array}{l}\text { Bacteria from organic } \\
\text { foods, including Bacillus } \\
\text { cereus and E. faecalis }\end{array}$ & Cetrimide and chlorhexidine & $\begin{array}{l}\text { Ceftazidime and cefotaxime, } \\
\text { among others }\end{array}$ & $\begin{array}{l}\text { Serial inoculation (up to } 20 \text { passages) on Tryptic Soy } \\
\text { Broth (TSB) media supplemented with a range of } \\
\text { concentrations of the biocides. }\end{array}$ \\
\hline [29] & $\begin{array}{l}\text { Bacteria from organic } \\
\text { foods, mainly from } \\
\text { Bacillus spp. Enterococcus } \\
\text { spp. and Staphylococcus } \\
\text { spp. }\end{array}$ & $\begin{array}{l}\text { BAC and hexadecylpyridinium } \\
\text { chloride }\end{array}$ & $\begin{array}{l}\text { Ampicillin, sulfamethoxazole, } \\
\text { cefotaxime }\end{array}$ & $\begin{array}{l}\text { Serial inoculation (up to } 20 \text { passages) on TSB } \\
\text { supplemented with a range of concentrations of the } \\
\text { biocides. }\end{array}$ \\
\hline [38] & Klebsiella pneumoniae & Chlorhexidine & Colistin & $\begin{array}{l}\text { Serial inoculation (up to } 6 \text { passages) in the presence of } \\
\text { the biocide. }\end{array}$ \\
\hline [39] & $\begin{array}{l}\text { E. coli, C. coli, S. enterica, } \\
\text { L. monocytogenes }\end{array}$ & $\begin{array}{l}\text { Didecyl dimethyl ammonium } \\
\text { chloride }\end{array}$ & $\begin{array}{l}\text { Ampicillin, cefotaxime, } \\
\text { ceftazidime, chloramphenicol } \\
\text { and ciprofloxacin }\end{array}$ & $\begin{array}{l}\text { The strains were daily exposed to increasing sub - } \\
\text { inhibitory concentrations of the biocide for } 7 \text { days. }\end{array}$ \\
\hline [21] & C. jejuni & $\begin{array}{l}\text { Trisodium phosphate, sodium } \\
\text { hypochlorite, acetic acid and a } \\
\text { commercial alkaline biocide }\end{array}$ & Kanamycin, streptomycin & $\begin{array}{l}\text { Serial inoculation (several passages) in the presence of } \\
\text { the biocides. }\end{array}$ \\
\hline
\end{tabular}


which contains sodium lauryl

ether sulfate, linear alkyl benzene

sulfonic acid, sodium salt,

propylene glycol monomethyl

ether, and dipropylene glycol $n$ -

propyl ether

mixture of aldehydes and QAC; a

\begin{tabular}{|c|c|c|c|c|}
\hline [9] & $\begin{array}{l}\text { S. enterica serovar } \\
\text { Typhimurium }\end{array}$ & $\begin{array}{l}\text { QAC; an oxidative compound; a } \\
\text { halogenated tertiary amine } \\
\text { compound }\end{array}$ & $\begin{array}{l}\text { Nalidixic acid, ciprofloxacin, } \\
\text { chloramphenicol, tetracycline }\end{array}$ & $\begin{array}{l}\text { Bacterial cultures were repeatedly sub-cultured over } 4 \\
\text { days (eight subcultures) in each biocide. }\end{array}$ \\
\hline [8] & $\begin{array}{l}\text { S. enterica serovar } \\
\text { Typhimurium }\end{array}$ & $\begin{array}{l}\text { a mixture of aldehydes and QAC; } \\
\text { a halogenated tertiary amine } \\
\text { compound }\end{array}$ & $\begin{array}{l}\text { Nalidixic acid, } \\
\text { chloramphenicol, tetracycline, } \\
\text { ciprofloxacin }\end{array}$ & $\begin{array}{l}\text { After } 5 \text { hours exposure to biocides, live cells were } \\
\text { sorted by flow cytometry and their AMR profile was } \\
\text { assessed. }\end{array}$ \\
\hline [40] & $\begin{array}{l}\text { S. enterica serovar } \\
\text { Typhimurium }\end{array}$ & $\begin{array}{l}\text { a blend of oxidizing compounds; } \\
\text { a QAC containing formaldehyde } \\
\text { and glutaraldehyde; a biocide } \\
\text { composed of organic acids and } \\
\text { surfactants }\end{array}$ & $\begin{array}{l}\text { Ciprofloxacin, } \\
\text { chloramphenicol, tetracycline, } \\
\text { and ampicillin }\end{array}$ & $\begin{array}{l}\text { Strains were passaged daily for } 7 \text { days in sub-inhibitory } \\
\text { concentrations, and separately for } 16 \text { days in gradually } \\
\text { increasing concentrations of the biocides. }\end{array}$ \\
\hline [41] & $\begin{array}{l}\text { S. enterica serovar } \\
\text { Typhimurium }\end{array}$ & an aldehyde based disinfectant & Ciprofloxacin & $\begin{array}{l}\text { Agar plates containing the biocide were inoculated } \\
\text { with the microbial suspension and incubated for up to } \\
7 \text { days. Then, some isolates were randomly selected } \\
\text { and characterized. }\end{array}$ \\
\hline
\end{tabular}




\section{FIGURE LEGENDS}

Fig. 1. Schematic overview of the main sources of antimicrobials and routes of transmission of antimicrobial resistance along the food chain. 